\title{
PROOF OF A MONOTONICITY CONJECTURE
}

\author{
Xun-Tuan Su
}

Abstract. Bennett gave a generalization of Schur's theorem to study various moment-preserving transformations. In this paper, we confirm a monotonicity conjecture of Bennett which is related to the generalized Schur's theorem and Haber's inequality.

Mathematics subject classification (2010): 05A20, 30E05.

Keywords and phrases: Symmetry, unimodality, Schur's theorem.

\section{REFERENCES}

[1] G. Bennett, Hausdorff means and moment sequences, Positivity, 15 (2011) 17-48.

[2] G. BennetT, Mercer's inequality and totally monotonic sequences, Math. Ineq. \& Appl. 14 (2011) 747-775.

[3] F. BRENTI, Log-concave and unimodal sequences in algebra, combinatorics, and geometry: an update, Contemp. Math. 178 (1994) 71-89.

[4] L. Comtet, Advanced Combinatorics, Reidel, Dordrecht, 1974.

[5] S. HABER, An elementary inequality, Int. J. Math. Math. Sci. 2 (1979) 531-535.

[6] G. H. Hardy, J. E. Littlewood, G. Pólya, Inequalities, Cambridge University Press, Cambridge, 1952.

[7] H. Y. L. Liang, L. Mu, Y. WANG, Catalan-like numbers and Stieltjes moment sequences, Discrete Math. 339 (2016) 484-488.

[8] A. D. MerCer, A note on a paper by S. Haber, Int. J. Math. Math. Sci. 6 (1983) 609-611.

[9] I. PAK, G. PAnOva, Strict unimodality of $q$-binomial coefficients, C. R. Acad. Sci. Paris, Ser. I, 351 (2013) 415-418. A corrigendum at: www .math.ucla.edu/ pak/papers/StrictCR.pdf.

[10] J. A. Shohat, J. D. Tamarkin, The Problem of Moments, Amer. Math. Soc., New York, 1943.

[11] R. P. STANLEY, Log-concave and unimodal sequences in algebra, combinatorics and geometry, Ann. New York Acad. Sci. 576 (1989) 500-534.

[12] X.-T. Su, Y. WANG, On unimodality problems in Pascal's triangle, Electron. J. Combin. 15 (2008), Research Paper 113, 12 pp.

[13] X.-T Su, Y. WAng, Proof of a conjecture of Lundow and Rosengren on the bimodality of p, $q$ binomial coefficients, J. Math. Anal. Appl. 391 (2012) 653-656.

[14] H. Sun, Y. WAng, H.-X. ZHAng, Polynomials with palindromic and unimodal coefficients, Acta Math. Sinica. 31 (2015) 565-575.

[15] Y. WAng, B.-X. ZHU, Log-convex and Stieltjes moment sequences, Adv. in Appl. Math. 81 (2016) $115-127$.

[16] D. V. WIDDER, The Laplace Transform, Princeton University Press, Princeton, 1946.

[17] F. ZANELLO, Zeilberger's $\mathrm{KOH}$ theorem and the strict unimodality of $q$-binoimial coefficients, Proc. Amer. Math. Soc. 143 (2015) 2795-2799. 